\title{
ANÁLISE DO FATOR DE SEGURANÇA DA ESTABILIDADE DAS VERTENTES NA BACIA DO RIO JACAREÍ, SERRA DO MAR PARANAENSE
}

\section{SAFETY FACTOR STABILITY ANALYSIS OF RIO JACAREÍ BASIN HILLSLOPES - SERRA DO MAR PARANAENSE}

Claudinei Taborda da Silveira
(DeGeog - UFPR) - Av. Cel. Francisco H dos Santos, 100 - Centro Politécnico - Bloco Setor de Ciências da Terra -
Departamento de Geografia, Universidade Federal do Paraná, CEP 81531-980 - Caixa Postal 19099 - Curitiba/PR -
e-mail: claudineits@ufpr.br

Alberto Pio Fiori

(DeGeol - UFPR) - Av. Cel. Francisco H dos Santos, 100 - Centro Politécnico - Bloco Setor de Ciências da Terra Departamento de Geologia - Universidade Federal do Paraná, CEP 81531-980 - Caixa Postal 19011 - Curitiba/PR -

e-mail:fiori@ufpr.br

Antonio Marcos Ferreira

Rua La Salle, 515 -Curitiba/PR, CEP81880-400 - e-mail:amf.geo@gmail.com

Rogério da Silva Felipe

Mineropar SA. - Rua Máximo João Kopp, 274 - Bloco 3, Curitiba/PR, CEP 82630-900 e-mail:rfelipe@mineropar.pr.gov.br

José Luiz Kepel Filho

Rua Vidal Natividade da Silva, 184 - Curitiba/PR - CEP 82900-110-e-mail: zehkepel@gmail.com

Rodrigo Marques Folador

Rua Mateus Leme, 834, ap. 32D - Curitiba/PR - CEP 80530-010 - e-mail: rmfolador@hotmail.com

Luis Carlos Costa

Rua Hemitério Torres, 76 - Campo Magro - CEP 85535-000 - e-mail: luiz_carlos.costa@hotmail.com

Informações sobre o Artigo

Data de Recebimento:

03/12/2011

Data de Aprovação:

01/06/2012

Palavras-chave:

Deslizamentos, teoria de

equilíbrio limite, mapeamento de susceptibilidade.

\section{Keywords:}

Landslides, limit equilibrium, susceptibility mapping.

\begin{abstract}
Resumo
O trabalho tem como objetivo a analise do fator de segurança (FS) da estabilidade das vertentes, face à susceptibilidade de ocorrência de processos de deslizamentos. O modelo preditivo utiliza-se de método determinístico, amparado na teoria de equilíbrio limite. A área de estudo é a bacia hidrográfica do rio Jacareí, localizada nos municípios de Morretes/PR e Paranaguá/PR, cujas vertentes estão situadas na Serra do Mar Paranaense. A escolha da área justifica-se pela sua representatividade e por essa ter sido fortemente afetada por processos de movimentos de massa ocorridos no dia 11 de março de 2011, e que ocasionaram diversos danos e prejuízos à população da região. Assim, por meio da modelagem do FS, obtido em função das propriedades físicas e mecânicas dos solos, formas de relevo e cobertura vegetal, integradas em um Sistema de Informações Geográficas (SIG), foi elaborado um mapa de susceptibilidade a processos de deslizamento
\end{abstract}


e hierarquização dos graus de estabilidade/instabilidade por meio dos valores do FS. A validação do método foi feita por meio do mapeamento das cicatrizes de deslizamentos deixadas após o evento na imagem de satélite de alta resolução WordView1 e comparação com o modelo preditivo. O modelo considerou as vertentes em estado de saturação hídrica, condizentes com a situação hidrológica para o dia do evento. Verificou-se que as classes com valores inferiores a 1,25, que expressam muito alta susceptibilidade a processos de deslizamentos, coincidiram em $81 \%$ com as cicatrizes mapeadas. Quando considerado o FS inferior a 1,50, que caracteriza alta susceptibilidade aos processos, o modelo preditivo coincidiu com $92 \%$ das cicatrizes. Portanto, o trabalho demonstrou que a modelagem do FS associada a ferramentas de SIG apresentam um grande potencial para mapeamento de susceptibilidade a deslizamentos nas vertentes da Serra do Mar Paranaense.

\begin{abstract}
This paper has objective to analyze safety factor (FS) of slope stability, in view of landslide process occurrence in the studied area. The predictive model uses the deterministic method, supported limit equilibrium model. The study area is the Jacareí river basin, located at Morretes/PR and Paranaguá/PR, witch strands are located at Serra do Mar Paranaense. The choice for this region is justified for it's representativity and for that it was affected by severe landslides occurred on march's 11, 2011, which occasioned several damages and losses to the local community. Therefore, using the FS modeling with, the soil physical and mechanical proprieties, vegetation coverage and relief forms, integrated on a geographic information system (GIS), a landslide susceptibility and instability/stability grades map using FS values was prepared. The model validation was done by using landslide scars mapping, based on a high resolution WordView1 image, taken after the event, and compared with the predictive map. The model was prepared using saturated strands values, consistent with the hydrological situation on the day of the event. It was found that the classes with FS values of less than 1.25, which express very high susceptibility to landslides processes coincided $81 \%$ with the scars mapped. When considering the FS less than 1.50 , which featuring high susceptibility to records, the predictive model coincided with $92 \%$ of scars. Therefore, the study demonstrated that the FS associated with modeling GIS tools have great potential for mapping susceptibility landslides on slopes of the Serra do Mar Paranaense.
\end{abstract}

\section{Introdução}

Na análise dos processos de deslizamentos translacionais, as vertentes apresentam-se, do ponto de vista teórico, como uma massa de solo submetida a três campos de forças distintos: o peso do material sobre a vertente, a força devido o fluxo de água e a resistência ao atrito. $\mathrm{O}$ estudo da estabilidade leva em conta a condição de equilíbrio entre esses três campos e envolve um conjunto de procedimentos que visam a determinação de um índice, ou de uma grandeza, que permita quantificar o grau de estabilidade das vertentes aos processos morfodinâmicos.

A análise baseada na teoria de equilíbrio limite considera que as forças que tendem a induzir a ruptura são exatamente balanceadas pelos esforços resistentes. A fim de comparar a estabilidade das vertentes em condições diferentes de equilíbrio é definido o Fator de Segurança (FS), índice obtido da razão entre as forças resistentes ao deslizamento e a resultante das forças solicitantes. A condição especial de equilíbrio-limite corresponde a um FS de valor igual a 1,00, e nesse caso, o escorregamento é eminente. Quanto maior for o valor acima da unidade, maior a estabilidade da vertente e, por consequência, menor a susceptibilidade de ocorrência desse processo.

Fiori e Carmignani (2009) tratam de forma detalhada diversos métodos determinísticos para o cálculo do fator de segurança, em diferentes perfis de vertentes. As equações propostas por esses autores descrevem o fator de segurança em função de propriedades físicas e mecânicas dos solos, relevo, escoamento hídrico e tipos de cobertura vegetal.

A espacialização das equações pode ser realizada por meio de um Sistema de Informações Geográficas (SIG) para armazenamento e diversas operações, onde são empregadas técnicas geomorfométricas tendo por base um Modelo Digital do Terreno (MDT) para a análise das vertentes.

Aplicações das técnicas de SIG para espacialização das equações de FS foram empregadas por Fiori (1995a), Fiori (1995b), Girardi (1999), Nunes (2002), Fiori e Nunes (2003), Amaral (2003), Borchardt (2005), Kosziak (2005), Tabalipa (2008). Há também rotinas computacionais customizadas para a aplicação do fator de segurança em SIG, cabe destacar dois exemplos amplamente difundidos, o SHALSTAB e o SINMAP. O SHALSTAB teve seu desenvolvimento nos EUA (MONTGOMERY e DIETRICH, 1994; DIETRICH e MONTGOMERY, 1998), no Brasil já foi empregado em diversos trabalhos, alguns exemplos são Fernandes et al. (2001), Fernandes et al.(2004), Guimarães (2000), Guimarães et al. (2003), Ramos et al. (2007), Vieira (2007), dentre diversos outros. O SINMAP (PACK et al., 1998a, PACK et al., 1998b e PACK et al., 2001) é também amplamente empregado. As rotinas customizadas facilitam a aplicação do FS pois resolvem todas as fases de processamento, no entanto o emprego da equação em SIG sem fazer uso das rotinas pré-determinadas permite ao operador maior liberdade 
no tratamento e inclusão das variáveis consideradas no FS. Em comum, todos demonstraram potencialidade de modelagem da estabilidade de vertentes empregando recursos de geoprocessamento em ambiente SIG.

Assim, o objetivo do presente trabalho é o mapeamento de susceptibilidade a deslizamentos por meio da modelagem do fator de segurança com base em modelo determinístico na análise da estabilidade de vertentes. Foi selecionada como área de estudo a bacia hidrográfica do rio Jacareí, cuja área é de 40,17 km², situada nos municípios de Morretes e Paranaguá, na Serra do Mar e Litoral Paranaense (Figura 1).

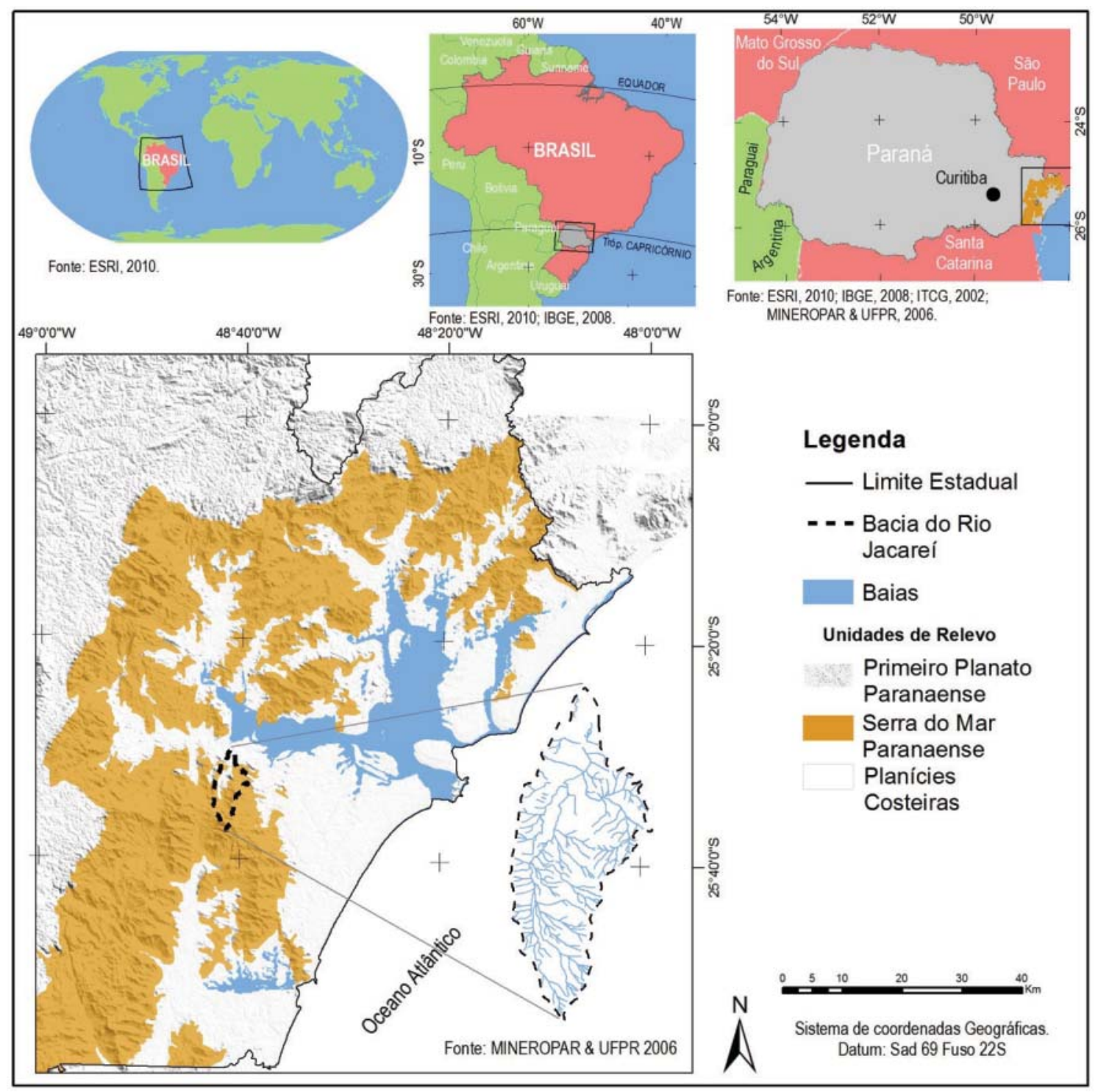

Figura 1 - Mapa ilustrativo da localização da Bacia do Rio Jacareí

A seleção da área de estudo está associada à sua relevância no episódio ocorrido no dia 11 de março de 2011, quando ocorreu na região central da Serra do Mar Paranaense um conjunto catastrófico e simultâneo de deslizamentos essencialmente translacionais, corridas de detritos e corridas de lama, associadas a inundações e depósitos na planície.
Os deslizamentos nessa bacia ocorreram predominantemente no terço superior das vertentes da Serra da Prata, em solos rasos, vertentes declivosas e associados a elevados valores de pluviosidade. Segundo Fernandes e Amaral (1996) é comum a ocorrência desse tipo de processo em profundidades de solo que variam entre $0,5 \mathrm{~m}$ e 5,0 $\mathrm{m}$, sendo que as rupturas tendem a ocorrer rapidamente devido ao rápido aumento da poro-pressão positiva durante eventos de precipitação muito intensa. 
O volume de material desprendido dos deslizamentos consistiu em blocos rochosos, solo e árvores, uma vez que toda a área estava recoberta pela Floresta Atlântica. A bacia do rio Jacareí foi uma das áreas mais afetadas, principal- mente na margem direita (Figura 2). A área calculada das cicatrizes dos escorregamentos, resultantes após o evento foi de $2,34 \mathrm{~km}^{2}$.

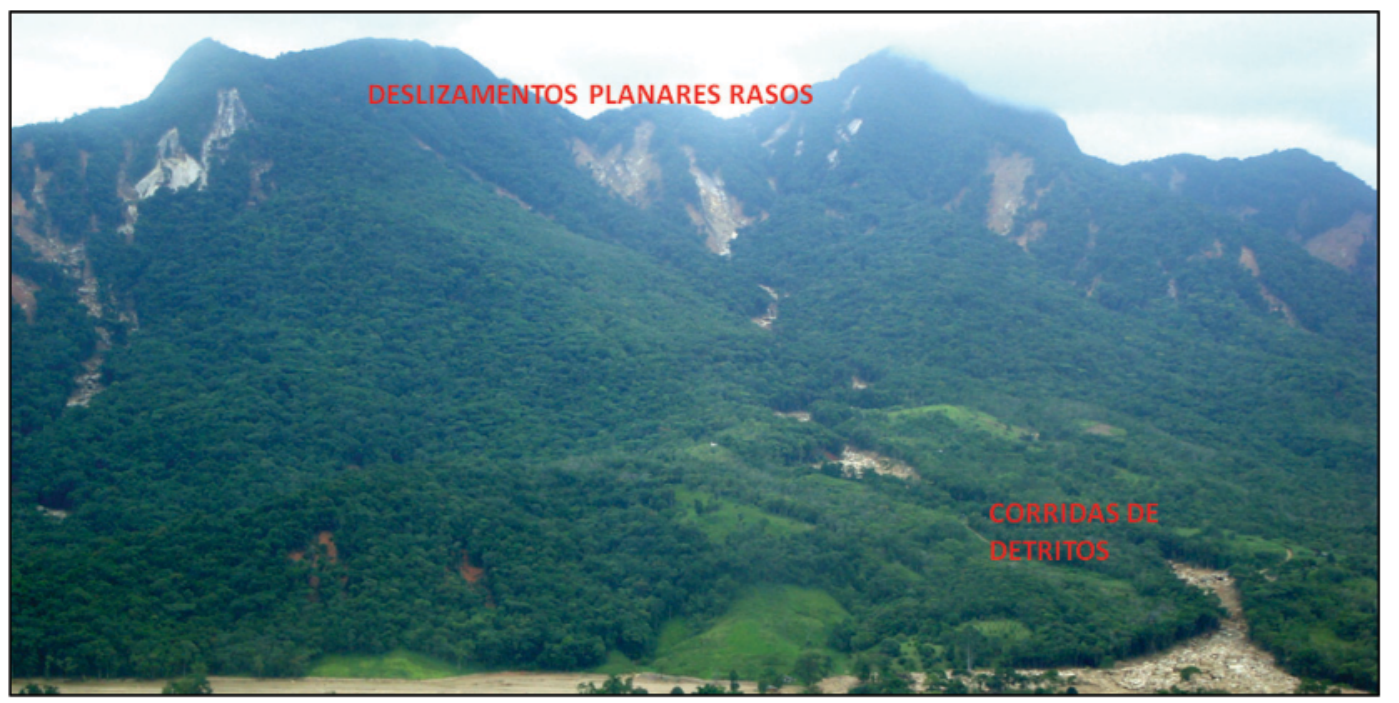

Figura 2 - Vertentes da margem direita da bacia do jacarei que sofreram processos de deslizamentos e corridas de detritos, ocorrido em $11 / 03 / 2011$

Fonte: Oscar Salazar Jr., Março de 2011

Os processos que ocorreram em consequência dos deslizamentos foram corridas de detritos, quanto o material desprendido, constituído por blocos de rochas de dimensões variadas, sedimentos arenosos e argilosos, além de grande quantidade de troncos, galhos e raízes das árvores, foram transportados ao longo das vertentes convergentes, remobilizando também depósitos pretéritos nos vales. Todo o volume fluiu em direção as planícies, com o material mais grosseiro tendendo a se depositar na saída dos canais, formando cones de detritos, enquanto que o material lenhoso e os sedimentos finos, na forma de lama, atingiram grandes extensões, levando à inundação e formação de depósitos de sedimentos finos em expressiva área da planície aluvial.

$\mathrm{O}$ evento resultou em grandes prejuízos à população do distrito de Floresta, residentes nessa bacia, pela destruição total ou parcial de casas, ruas, estradas, pontes, lavouras, etc e, tragicamente, em um óbito. A população local teve que abandonar suas casas e o abastecimento de água e luz foi prejudicado. Os maiores danos foram causados na planície, cuja área concentra a maior ocupação na bacia. Assim, o episódio demonstrou a neces- sidade de estudos na região envolvendo o entendimento de processos de movimento de massa, o que motivou a realização do presente trabalho e sua abordagem no estudo de deslizamentos.

\section{Método}

Os procedimentos empregados consistiram na organização da base de dados, armazenamento e realização das operações para o equacionamento do FS das vertentes em ambiente SIG. Para tal empregou-se o software ArcGis versão 10 (ESRI, 2010).

Os resultados previsionais do FS foram validados por meio de comparação com as cicatrizes de deslizamentos, delineadas e mapeadas com base na imagem de satélite WordView1, resolução espacial de 0,6 metros, datada de 05 de maio de 2011 e, portanto, com imageamento posterior ao episódio ocorrido em 11 de março de 2011. A Figura 3 mostra os polígonos das cicatrizes identificadas na imagem de satélite, bem como os contornos na delimitação dos deslizamentos. 


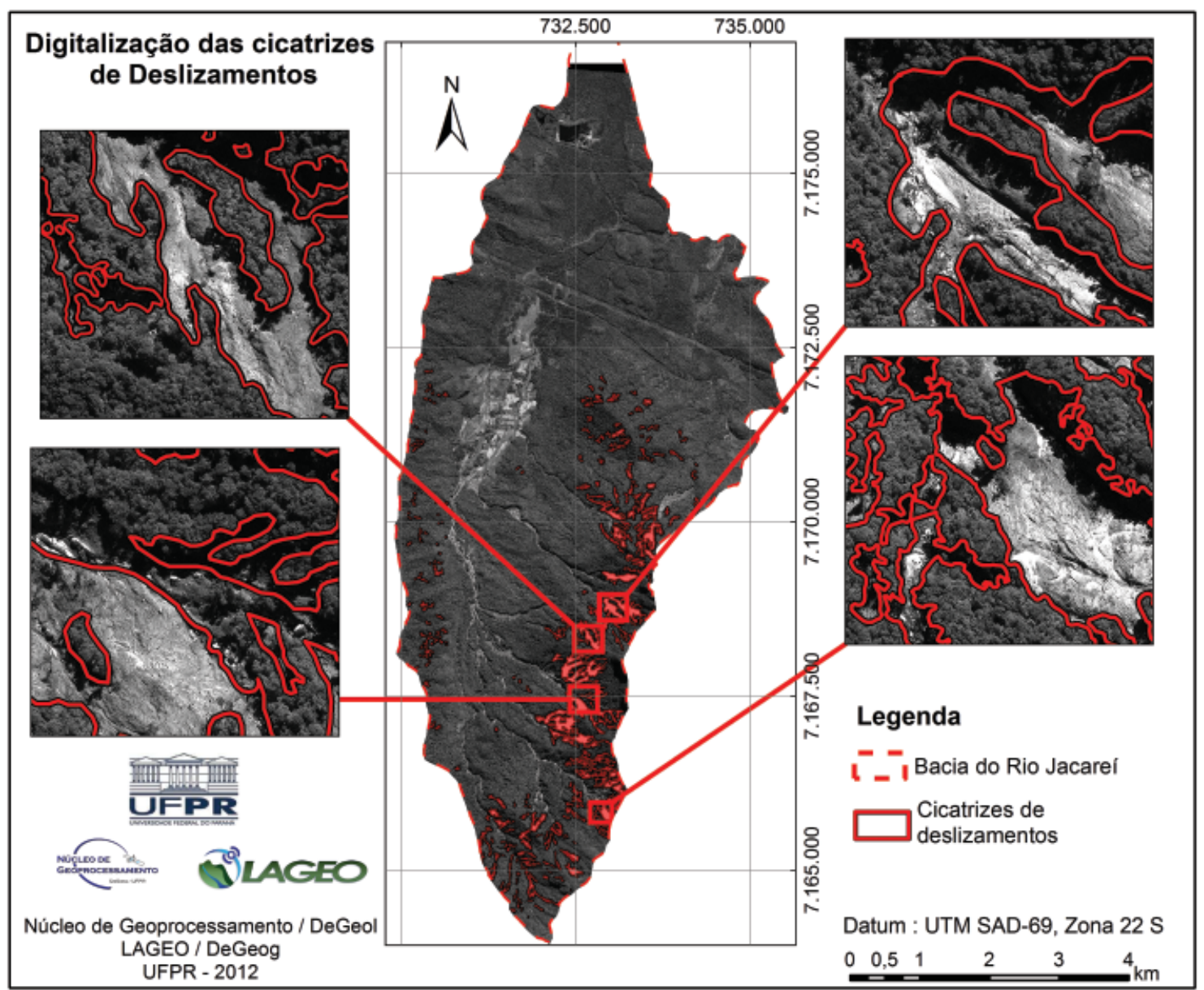

Figura 3 - Delimitação das cicatrizes de deslizamentos na imagem de satélite

Fonte: imagem de satélite wordview1, imageamento em 05 de maio de 2011.

\section{O Fator de Segurança (FS)}

O método utilizado para a determinação da susceptibilidade a deslizamentos nas vertentes segue a proposta apresentada por Fiori e Carmignani (2009), efetuada por meio de método determinístico, baseado no conceito de equilíbrio-limite. O FS resultante representa a razão das forças favoráveis ao movimento pelas forças resistentes. Foram consideradas as características das vertentes, dos solos, a ação da força do vento e a hidrologia das vertentes. No que diz respeito à cobertura vegetal, apenas não foi tomada em consideração o efeito de atirantamento, ou de ancoramento das raízes, uma vez que os planos de ruptura dos deslizamentos observados na área de estudo situavam-se abaixo das raízes. A equação1 apresenta a expressão empregada e a Figura 4 representa, de modo esquemático, as variáveis consideradas:

$$
\mathrm{FS}=\frac{\operatorname{Cs}\left[\left(\text { Ysat }-\frac{\mathrm{hw}}{\mathrm{h}} \mathrm{Ya}\right) \mathrm{h} \operatorname{cosi}+\sigma \mathrm{a} \operatorname{cosi}\right] \operatorname{ran} \varphi}{(\text { hynat }+\sigma a) \sin i+\sigma v e}(\text { equação1) }
$$

Onde:

FS = Fator de segurança;

$\mathrm{CS}=$ Coesão do solo $(\mathrm{kPa})$;

Ysat $=$ Peso específico do solo saturado $\left(\mathrm{kN} / \mathrm{m}^{3}\right)$;

Ynat $=$ Peso específico natural do solo $\left(\mathrm{kN} / \mathrm{m}^{3}\right)$;

$\mathrm{hw}=$ Altura da zona de solo saturado, perpendicular à vertente $(\mathrm{cm})$; $\mathrm{h}=$ Altura da zona de solo não saturado, perpendicular à vertente $(\mathrm{cm})$;

$\mathrm{Z}=$ Espessura do solo, medido na vertical $(\mathrm{cm})$;

Ya $=$ Peso específico da água $\left(\mathrm{kN} / \mathrm{m}^{3}\right)$;

$\mathrm{i}=$ Inclinação da vertente (graus);

$\sigma \mathrm{a}=$ Pressão exercida sobre a vertente pelo peso das árvores $(\mathrm{kPa})$;

$\varphi=$ Ângulo de atrito interno do solo (graus)

$\sigma \mathrm{ve}=$ Pressão exercida pelo vento na cobertura vegetal $(\mathrm{kPa})$. 


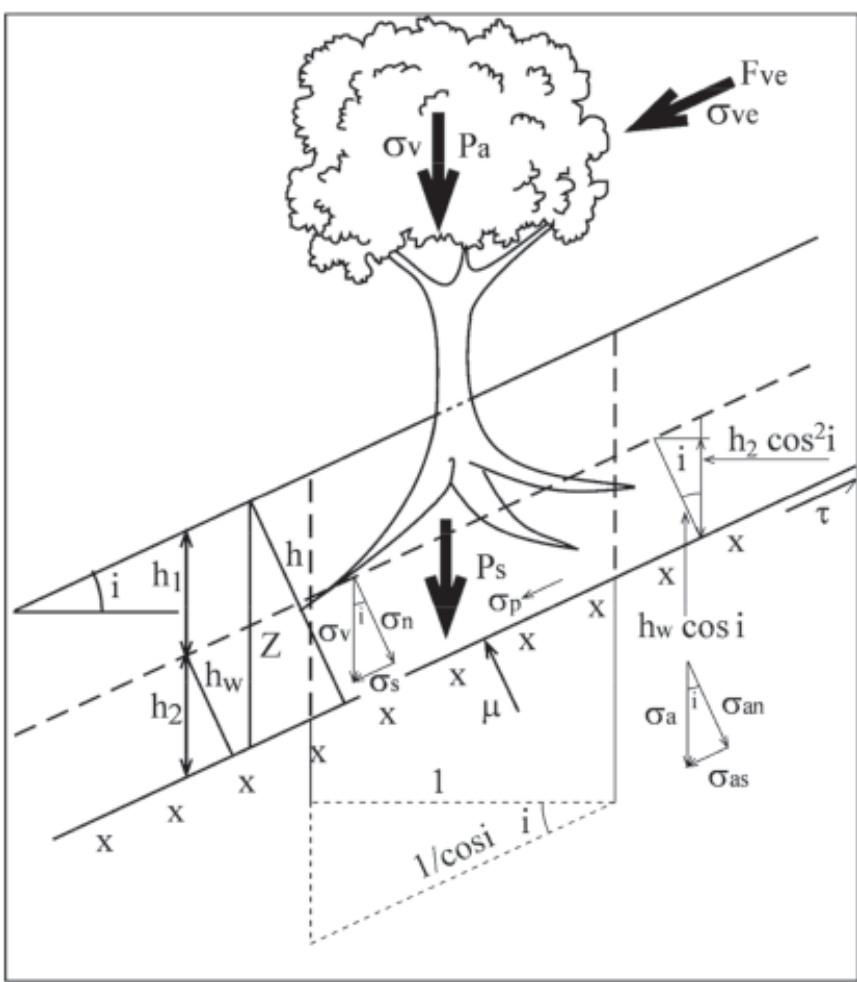

Figura 4 - Representação dos fatores atuantes na estabilidade das vertentes considerados no fator de segurança

Fonte: Fiori e Carmignani (2009)

Os parâmetros de solos utilizados basearam-se nos ensaios de cisalhamento direto realizados por Kosziak (2005), na bacia hidrográfica do rio Marumbi, cujos valores do ângulo de atrito interno do solo $(\varphi)$, peso específico do solo saturado ( $\gamma$ sat) e a coesão do solo (Cs), foram obtidos em amostras indeformadas coletadas com base nas classes de solos. Nas áreas de ocorrência de Neossolos Litólicos, e suas associações, os valores considerados foram: $\varphi=23,5^{\circ}$, $\gamma \mathrm{sat}=17,29 \mathrm{kN} / \mathrm{m}^{3}$ e $\mathrm{Cs}=17 \mathrm{kPa}$; nas classes de Cambissolos: $\varphi=23,2^{\circ}, \gamma_{\mathrm{sat}}=16,38 \mathrm{kN} / \mathrm{m}^{3}$ e $\mathrm{Cs}=14,8 \mathrm{kPa}$; nas classes de Latossolos e Argissolos e suas associações: $\varphi=21,7^{\circ}$, $\gamma \mathrm{sat}=17,16 \mathrm{kN} / \mathrm{m}^{3}$ e Cs $=13,5 \mathrm{kPa}$ e nas áreas de Gleissolos: $\varphi=25,5^{\circ}, \gamma s a t=18,45 \mathrm{kN} / \mathrm{m}^{3}$ e $\mathrm{Cs}=10,9 \mathrm{kPa}$. Essa última classe ocorre nas planícies, isenta de escorregamentos, no entanto foram incorporadas para contemplar integralmente o recorte geográfico da bacia hidrográfica.

Os valores amostrais dos ensaios foram extrapolados para toda a área da bacia segundo a distribuição de unidades de solos de características similares aos amostrados por Kosziak (op. cit.). O emprego desses parâmetros se mostrou adequado, pois a área de levantamento das amostras apresenta características físico-naturais similares e se constituí de uma bacia hidrográfica adjacente à bacia do rio Jacareí.
As unidades de solos foram definidas por meio de inferência espacial, utilizando-se de técnicas pedométricas, apoiada na análise digital do relevo, segundo proposta de SILVEIRA (2011). As classes obtidas foram: Neossolos Litólicos, Associação Neossolos Litólicos + Cambissolos, Cambissolos, Associação Cambissolos + Argissolos, Associação Argissolos + Latossolos e Gleissolos, cujas espessuras adotadas para cada classe foram, respectivamente: 50, 75, 100, 175, 250, $325(\mathrm{~cm})$.

Quanto aos parâmetros que contemplam a influência da vegetação e o vento, foram adotados valores fixos para toda a região da bacia, baseados em valores médios, sendo que para a serra do mar os valores de são da ordem de 3,0kPa (WOLLE e PEDROSA, 1981) e os valores de são da ordem de 1,0 kPa (FENDRICH e FERREIRA, 1995).

A modelagem do FS empregado considera um evento de intensa precipitação, semelhante as condições do ocorrido no dia 11/03/2011, cujo valor registrado pela Estação Meteorológica Morretes (INMET), situada mais próxima da área afetada, foi de 230,6 mm. A Figura 5 apresenta os valores de precipitação diária e acumulada no período da primeira quinzena do mês de março de 2011, onde é possível verificar elevados valores acumulados de chuva, $230 \mathrm{~mm}$ em 24 horas, $305 \mathrm{~mm}$ em 48 horas e $382 \mathrm{~mm}$ em 72 horas. Devido ao elevado valor de precipitação acumulada até o dia do evento, somado ao forte aguaceiro que desencadeou os processos de deslizamentos, considerou-se o solo em estado de saturação na modelagem da equação de FS e, portanto, a razão $\frac{h 2}{\mathrm{Z}}$ foi tomada como unitária na equação1.

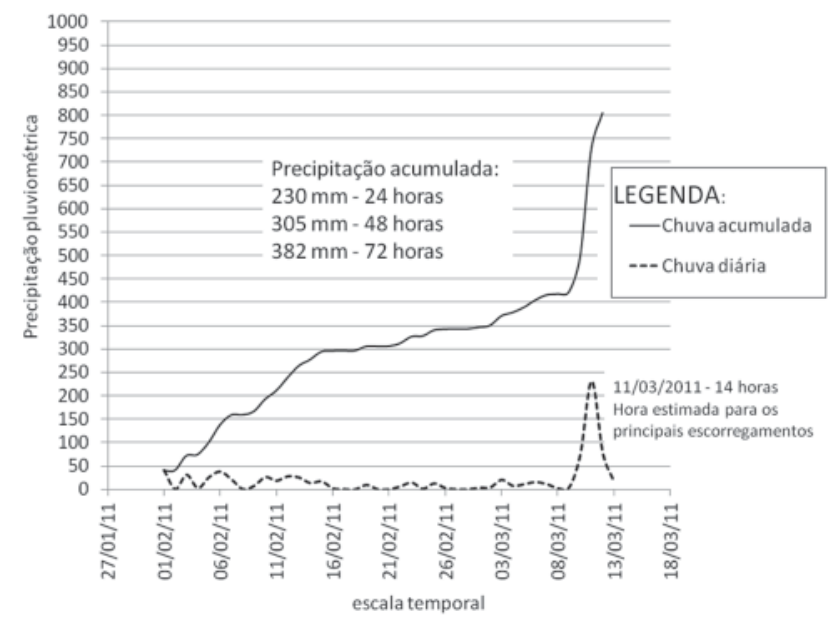

Figura 5 - Gráfico de precipitação diária e acumulada na região de estudo

Fonte: Estação morretes A873. Coordenadas: 25,5090 ${ }^{\circ}$ $48,8087^{\circ} w$, altitude $59 \mathrm{~m}$ (inmet, 2011);

Modificado de: Geoplanejamento Ltda (2011) 
A inclinação da vertente $(i)$ foi obtida de MDT, na estrutura de uma grade regular com resolução espacial de 5 metros, elaborado para a bacia a partir de uma base planialtimétrica na escala 1:10.000, elaborado por GEOPLANEJAMENTO SS LTDA (2011). A variável geomorfométrica foi gerada no software ArcGIS 10 (ESRI, 2010) por meio de janelas móveis $3 \times 3$ das derivadas direcionais do modelo proposto por Horn (1981).

\section{Resultados e discussões}

No modelo preditivo do fator de segurança as vertentes foram consideradas como em estado de saturação hídrica, dada as condições de elevada pluviosidade do dia 11 de março de 2011, e em função do acúmulo da precipitação dos dias que o antecederam. A modelagem empregada na análise da estabilidade das vertentes resultou em valores do FS discretizados em quatro classes. As classes compostas por valores de FS inferior a 1,25 representam áreas de muito alta susceptibilidade a deslizamentos, classes com valores entre 1,25 e 1,5 representam áreas de alta susceptibilidade, classes entre 1,5 e 2,0 representam moderada susceptibilidade e classes superior a 2,0, baixa susceptibilidade (Figura 6).

A representatividade de cada classe na bacia do rio Jacareí é apresentada na Tabela 1. É possível verificar que pouco mais que a quarta parte da bacia $\left(10,6 \mathrm{~km}^{2}\right.$ ou $26,36 \%$ do total da área) encontrava-se em estado eminente a deslizamentos, nas condições de saturação hídrica nas vertentes da Serra da Prata. Nessas mesmas condições, outra significativa área $\left(6,36 \mathrm{~km}^{2}\right.$ ou $15,81 \%$ do total da área) pode ser considerada como de alta susceptibilidade, com valores de FS entre 1,26 e 1,50. Somadas essas duas classes, verifica-se que mais de $40 \%$ da área, segundo o modelo, estaria susceptível aos eventos de deslizamentos nas condições do dia 11 de março.

Tabela 1 - Distribuição das classes do FS na bacia do Rio Jacareí

\begin{tabular}{|l|l|l|l|}
\hline Intervalos de FS & Classe de estabilidade aos deslizamentos & Área $\left(\mathrm{km}^{2}\right)$ & Ocorrência \% \\
\hline Inferior a 1,25 & $\begin{array}{l}\text { Muito baixa estabilidade } \\
\text { Muito alta susceptibilidade a deslizamentos }\end{array}$ & 10,6 & 26,36 \\
\hline $1,26-1,50$ & $\begin{array}{l}\text { Baixa estabilidade } \\
\text { Alto susceptibilidade a deslizamentos }\end{array}$ & 6,36 & 15,81 \\
\hline $1,51-2,00$ & $\begin{array}{l}\text { Intermediária estabilidade } \\
\text { Moderada susceptibilidade a deslizamentos }\end{array}$ & 5,08 & 12,65 \\
\hline$>2,0$ & $\begin{array}{l}\text { Estável } \\
\text { Baixa susceptibilidade a deslizamentos }\end{array}$ & 18,16 & 45,18 \\
\hline Total & & 40,20 & 100,00 \\
\hline
\end{tabular}

Quanto às feições de relevo que caracterizam as áreas mais instáveis, ou seja, as classes de muito alta susceptibilidade, situadas na margem direita do rio Jacareí, caracterizam-se por vertentes com declividades superiores a $30 \%$, em segmentos situados no terço superior e cujos valores altimétricos estão acima de 400 metros de altitude. As declividades e gradientes altimétricos nessas áreas são sustentados por rochas mais resistentes, associadas a maciços rochosos, como é o caso do Granito Morro Inglês (Figura 7). De acordo com Almeida e Carneiro (1998), a natureza petrográfica e estrutural dos granitos da Serra do Mar do Paraná os torna resistentes à erosão e sustentam destacadas elevações, resultando em elevado gradiente altimétrico e vertentes fortemente declivosas, como as que configuram a Serra da Prata. Assim, este cenário resulta em solos rasos pouco desenvolvidos, predominantemente os Neossolos Litólicos, propícios a processos de deslizamentos translacionais.

As áreas de muito alta susceptibilidade situadas na margem esquerda do rio Jacareí, que ocorrem em menor predominância, posicionam-se preferencialmente no terço médio das vertentes, em litologia metamórfica da Formação Rio das Cobras (Figura 7).

As áreas agrupadas na classe de alta susceptibilidade da margem direita ocupam preferencialmente as posições de terço médio a inferior das vertentes, em cotas hipsométricas inferiores a 400 metros e declividades menores, entre $20 \%$ e $30 \%$. Nesses casos os solos são mais espessos, em virtude da contribuição de material alóctone. Na margem esquerda essa classe prevalece nas posições de terço médio a superior das vertentes, com declividades em torno de $25 \%$.

$\mathrm{Na}$ bacia do rio Jacareí foram mapeadas 288 cicatrizes de deslizamentos na imagem do sensor orbital Wordview1, que representam 2,06 $\mathrm{km}^{2}$, ou $5,14 \%$ da área de estudo. Na comparação das classes obtidas pela aplicação do modelo preditivo, sobrepostas às áreas de cicatrizes identificadas, verificou-se que $81 \%$ das áreas de deslizamento coincidem com a classe de muito alta susceptibilidade, ou de FS inferior a 1,25, com maior concordância na região da Serra da Prata, margem leste do rio Jacareí. Quando consideradas as áreas com FS inferior a 1,50 a concordância foi de $92 \%$. 


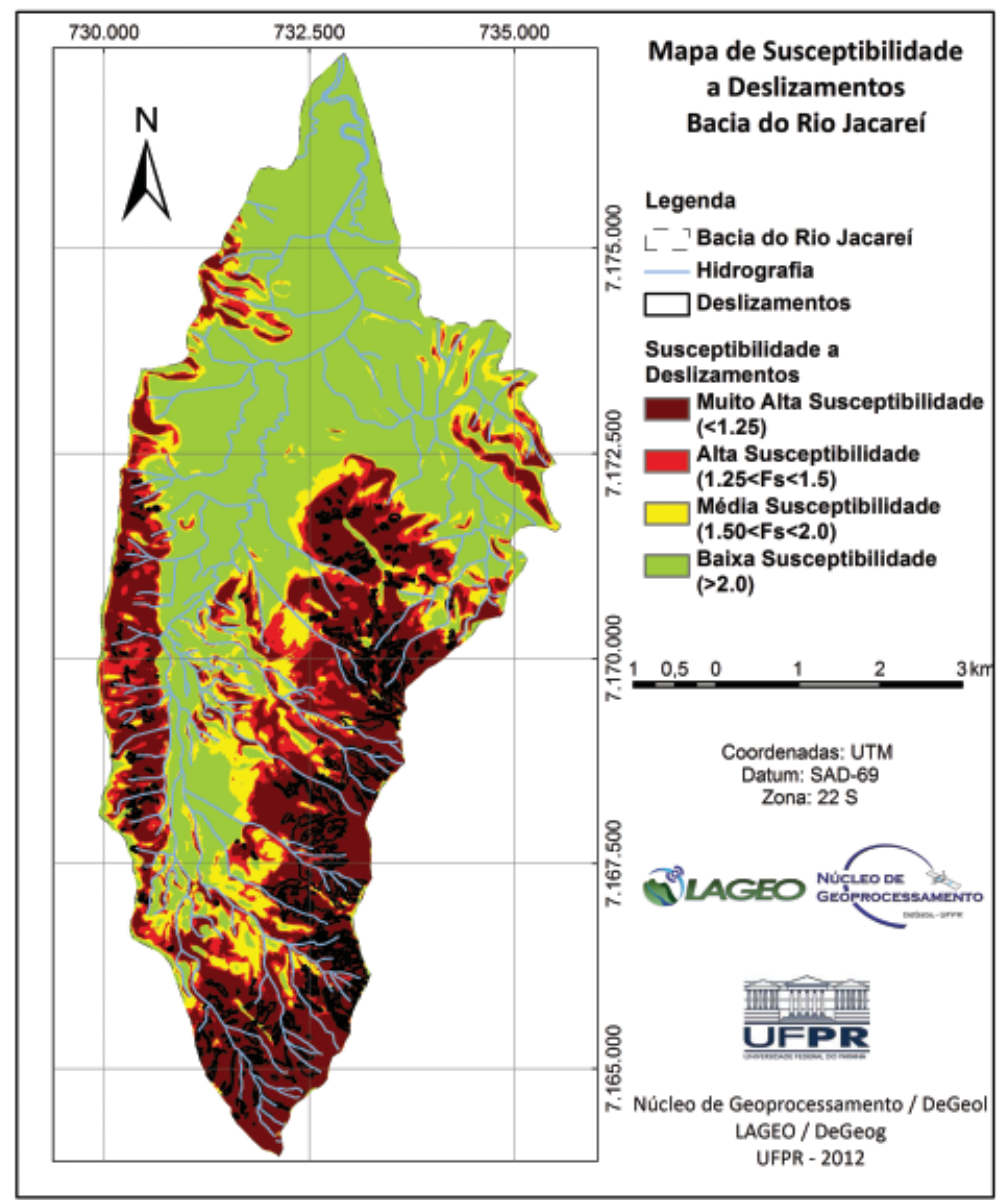

Figura 6 - mapa do fator de segurança da estabilidade das vertentes a deslizamentos

Uma grande parte das áreas de muito alta e alta susceptibilidade, no mapa apresentado na Figura 6, não coincidiram diretamente com as cicatrizes de escorregamentos do evento ocorrido no dia 11/03/2012, 63,88\% quando considerado o FS inferior a 1,25 , e $73,76 \%$ no caso do FS inferior a 1,50. Nessas situações, apesar de não ocorrer sobreposições, as áreas mostram-se instáveis, pois inserem-se no mesmo contexto de susceptibilidade. Exemplo dessa situação é mostrada na figura 8, onde ocorrem ilhas preservadas, cujo entorno é constituído por cicatrizes. $\mathrm{Na}$ figura $8 \mathrm{~b}$ foram delimitadas as áreas que não sofreram deslizamentos, porém devem ser consideradas instáveis.

Cabe destacar, apoiando-se nos apontamentos feitos por Almeida e Carneiro (1998), que os processos naturais no atual domínio da Serra do Mar, uma região submetida a altas pluviosidades anuais e episódios prolongados de precipitações, envolvem intensa participação nas movimentações de massa em seu natural processo de evolução morfogenética. Desse modo, as classes obtidas no mapa de susceptibilidade a deslizamento da bacia do rio Jacareí refletem adequadamente a dinâmica desse ambiente, em concordância com seu contexto regional.

O método empregado na avaliação da estabilidade de vertentes da Serra da Prata mostrou-se um instrumento valioso e adequado para a predição de áreas de susceptibilidade a escorregamentos translacionais e, consequentemente, para os estudos de prevenção de desastres naturais, em um ambiente em que atuam na evolução do relevo, de modo mais intenso, os processos morfoesculturais na forma de deslizamentos. 


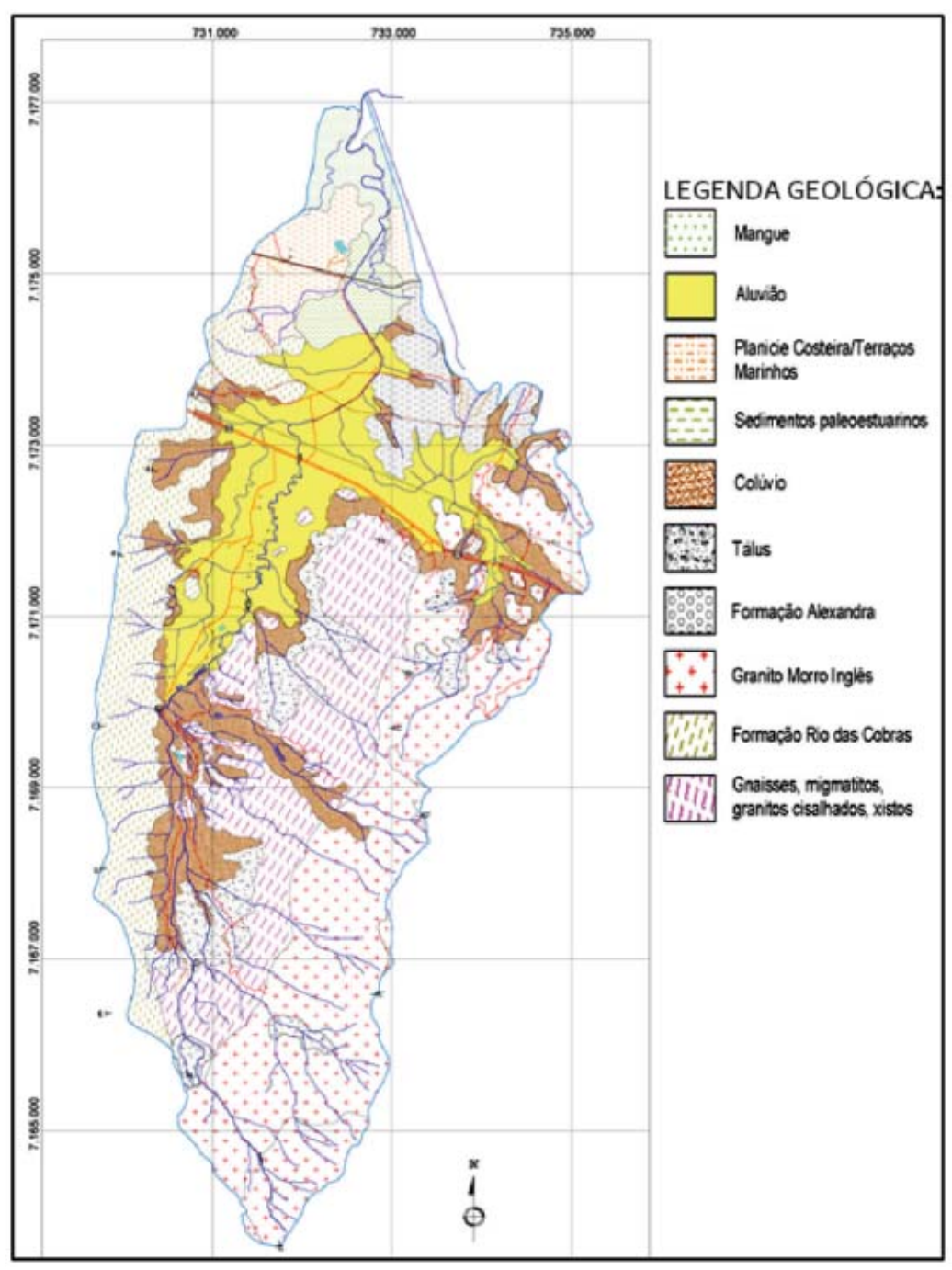

Figura 7 - Mapa geológico da bacia do Rio Jacareí, escala 1:10.000

Fonte: Geoplanejamento SS Ltda (2011)

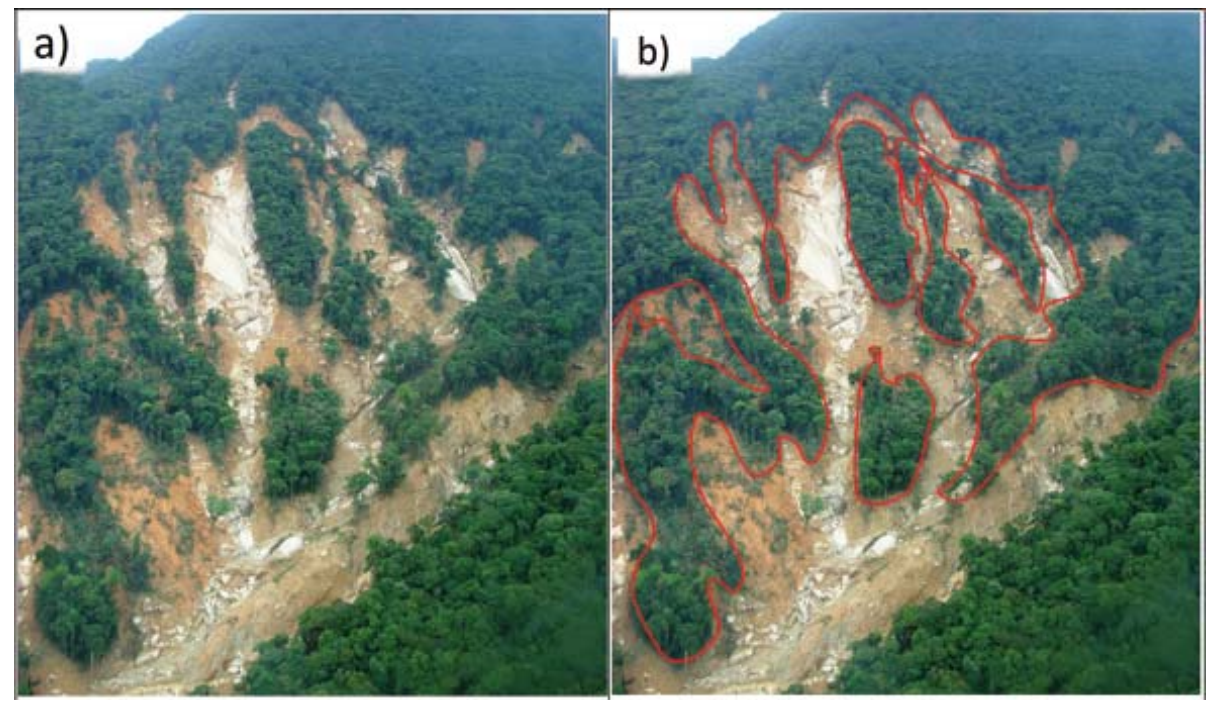

Figura 8 - Cicatrizes de deslizamentos

Nota: Afigura Bmostra a delimitação da área que não deslizou, mas que se apresentam inseridas na forma de ilhas preservadas no meio das cicatrizes.

Fonte: Alberto Pio Fiori, março de 2011 


\section{Conclusões}

O mapa gerado na modelagem do fator de segurança para análise da estabilidade das vertentes na bacia do rio Jacareí, apoiado no uso de SIG, demonstrou potencial na identificação e mapeamento de áreas susceptíveis a deslizamentos. A comparação do modelo previsional com as cicatrizes de deslizamentos verificadas por meio das imagens de satélite Wordview1, tomadas após a ocorrência de 11/03/2011, mostra um índice de $81 \%$ de acerto para um FS inferior a 1,25 e 92\% para um FS inferior a 1,50.

\section{Referências bibliográficas}

AMARAL, C. Grau de estabilidade das vertentes da Serra do Purunã nas proximidades do falso túnel. Dissertação. Curitiba, 2003. Dissertação (Mestrado em Geologia) - Setor de Ciências da Terra, Universidade Federal do Paraná.

ALMEIDA, F.F.M.; CARNEIRO, C.D.R. Origem e evolução da Serra do Mar. Revista Brasileira de Geociências, n.28, v.2, p.135-155, 1998.

BORCHARDT, N. Diagnóstico geológico-geotécnico na estabilidade de encostas do alto e médio curso da bacia do rio Sagrado. Curitiba, 2005. Dissertação (Mestrado em Geologia) Setor de Ciências da Terra, Universidade Federal do Paraná.

DIETRICH, W.E.; MONTGOMERY, D.R. SHALSTAB: a digital terrain model for mapping shallow landslide potential. NCASI (National Council of the Paper Industry for Air and Stream Improvement) Technical Report, February 1998, 29pp.

ESRI. ArcGis, Spatial Analyst, 3D Analyst. versão 10. Environmental Systems Research Institute. 2010

FENDRICH, R.; FERREIRA, M.A. Rosa de Freqüência dos Ventos no Estado do Paraná. Revista Acadêmica da PUC/PR. Vol. 11, p. 49-57, 1995.

FERNANDES, N.F.; AMARAL, C.P. Movimentos de massa: uma abordagem geológico - geomorfológico. In Guerra, A.J.T. e Cunha, S.B. (org) Geomorfologia e Meio Ambiente. Rio de janeiro: Bertrand, p.123-194, 1996.

FERNANDES, N.F.; GUIMARÃES, R.F.; GOMES, F.A.T.; VIEIRA, B.C.; MONTGOMETY, D.R.; GREENBERG, H. Condicionantes Geomorfológicos dos Deslizamentos nas Encostas: avaliação de metodologias e aplicação de modelo de previsão de áreas susceptíveis. Revista Brasileira de Geomorfologia, v.2, n.1, p.51-71, 2001.

FERNANDES, N.F.; GUIMARÃES R.F., GOMES R.A.T., VIEIRA B.C., MONTGOMERY D.R., GREENBERG H. Topographic controls of landslides in Rio de Janeiro: field evidences and modeling. Catena, n. 55, v. 2, p.163-181, 2004.

FIORI, A.P. Estudo da estabilidade de vertentes da área de Guaraqueçaba, Paraná. Boletim Paranaense de Geociências, v. 43, p. 25-40, 1995a.

FIORI, A.P. Fatores que influem na análise de vertentes e no movimento de massa em encostas. Boletim Paranaense de Geociências, v. 43, p. 7-24, 1995 b.

FIORI, A.P.; CARMIGNANI, L. Fundamentos de mecânica dos solos e das rochas. Aplicação na estabilidade de taludes. Curitiba: Editora da UFPR, Oficina de Textos. 2 ed., 2009, $602 \mathrm{p}$.

FIORI, A.P.; NUNES, F.G. Áreas de risco e dinâmica geoambiental das encostas da Serra do Mar - PR. Boletim Paranaense de Geociências, v. 53, p. 45-58, 2003.

GEOPLANEJAMENTO, Pesquisa Mineral e Geologia Ambiental SS Ltda. Mapeamento Geológico-Geotécnico da Porção Leste da Serra do Mar do Estado do Paraná. Relatório Técnico, 91p., 4 volumes. 2011.

GIRARDI, G. Análise preliminar da estabilidade de encostas e taludes de Almirante Tamandaré e Colombo. Curitiba, 1999. Dissertação (Mestrado em Geologia) - Setor de Ciências da Terra, Universidade Federal do Paraná.

GUIMARÃES, R.F. A modelagem matemática na avaliação de áreas de risco a deslizamentos: o exemplo das bacias dos rios Quitite e Papagaio (RJ). Rio de Janeiro, 2000. 157p. Tese (Doutorado em Geologia) - Universidade Federal do Rio de Janeiro.

GUIMARÃES, R.F.; MONTGOMERY, D.R.; GREENBERG, H.M.; FERNANDES, N.F.; GOMES, R.A.T.; CARVALHO JÚNIOR, O.A. Parameterization of soil properties for a model of topographic controls on shallow landsliding: application to Rio de Janeiro. Engineering Geology, v. 69, n. 1-2, p.99-108, 2003.

HORN, B. K. P. Hill shading and the reflectance map. Proceedings of the IEEE, n. 69, v. 01, p. 14-47, 1981.

INMET - Instituto Nacional de Meteorologia. Estação Morretes A873. Coordenadas: $25,5090^{\circ} \mathrm{S} 48,8087^{\circ} \mathrm{W}$, altitude $59 \mathrm{~m}$. 2011

KOZCIAK, S. Análise da estabilidade de vertentes na bacia do rio Marumbi- Serra do Mar - Paraná. Curitiba, 2005, 141p. Tese (Doutorado em Geologia) - Setor de Ciências da Terra, Universidade Federal do Paraná.

NUNES, F.G. Levantamento de áreas de riscos a partir da dinâmica geoambiental das encostas da Serra do Mar no Paraná. Curitiba, 2002, Dissertação (Mestrado em Geologia) Setor de Ciências da Terra, Universidade Federal do Paraná.

PACK, R.T.; TARBOTON, D.G.; GOODWIN, C.N. Terrain stability mapping with SINMAP, technical description and users guide for version 1.00. Report Number 4114-0, Terratech Consulting Ltd., Salmon Arm, Canada, 1998a, 68p.

PACK, R.T.; TARBOTON D.G.; GOODWIN, C.N. The SINMAP Approach to Terrain Stability Mapping. In.: 8th Congress of the 
International Association of Engineering Geology, Vancouver, British Columbia, p. 21-25, 1998 b.

PACK, R.T.; TARBOTON D.G.; GOODWIN, C.N. Assessing Terrain Stability in a GIS using SINMAP. In: 15th Annual GIS Conference, Vancouver, British Columbia, p. 1-9. 2011.

MONTGOMERY, D.R.; DIETRICH, W.E. A physically based model for the topographic control on shallow landsliding. Water Resources Research, v.30, n.4, p.1153-1171, 1994.

RAMOS, V.M.; GUIMARÃES, R.F.; REDIVO, A.L.; GOMES, R.A.T.; FERNANDES, N.F.; CARVALHO FILHO, O.A. Aplicação do modelo shalstab, em ambiente arcview para o mapeamento de áreas susceptíveis a escorregamentos rasos na região do Quadrilátero Ferrífero - MG. Espaço e Geografia, v.5, n.1, p.49-57, 2002.

TABALIPA, N.L. Mapeamento geoambiental do Município de Pato Branco, Paraná, como ferramenta para o planejamento territorial e ambiental. Curitiba, 2008. 243p. Tese (Doutorado em Geologia) - Setor de Ciências da Terra, Universidade Federal do Paraná.
VIEIRA, B.C. Previsão de escorregamentos translacionais rasos na Serra do Mar, (SP), a partir de modelos matemáticos em bases físicas. Rio de Janeiro, 2007. 193 p. Tese (Doutorado em Geografia) - Programa de Pós Graduação em Geografia, Universidade Federal do Rio de Janeiro.

WOLLE, C.M.; PEDROSA, J.A.B. Horizontes de Transição Condicionam Mecanismo de Instabilidade de Encostas na Serra do Mar. In: Congresso Brasileiro de Geologia de Engenharia, ABGE, Itapema/SC, vol. 2, p. 121-135, 1981.

\section{Agradecimentos:}

À Mineropar SA. pela concessão de três bolsas de estágio para fomentar o desenvolvimento da pesquisa.

À empresa Geoplanejamento Ltda por ceder o uso da imagem de satélite WordView1 e fornecer a base cartográfica planialtimétrica na escala 1:10.000.

Aos bolsistas envolvidos nos grupos de trabalho do Núcleo de Geoprocessamento/DeGeol e LAGEO/DeGeog - CT/UFPR 